\title{
Towards transportation system integration in the City of Tshwane Metropolitan Municipality
}

\author{
D. R. Diedericks \& J. W. Joubert \\ Department of Industrial \& Systems Engineering, \\ University of Pretoria, South Africa
}

\begin{abstract}
Past political regimes, the resulting urban planning, and extreme socio-economic imbalances have resulted in segregated disparate public transportation systems. Public transport only captures $50 \%$ of the passenger transport market with modes competing due to its fragmented nature and the deregulated planning functions. The paper contributes to the public transport body of knowledge as it introduces South African particularities, and proposes innovative interventions to overcome transport planning challenges.
\end{abstract}

Keywords: public transport, activity-based modeling, agent-based simulation.

\section{Introduction}

The City of Tshwane Metropolitan Municipality (CTMM) system attempts to serve not only a large low-income group commuting from the dormitory settlement on the outskirts of the metropolitan areas to the dispersed economic centres, but also public transport trips within the city centre simultaneously. Three modes of public transport compete due to the fragmented nature of the transportation system. Although a number of governmental interventions are planned to alleviate the current and increasing pressures on the public transport system as a whole, a number of future events, including the 2010 soccer world cup to be hosted by South Africa, have emphasised the need to focus attention on the reconsideration and redesign of the current public transport system. This paper proposes a framework to be used in the attempt to redesign the current disparate public transportation system and work towards a integrated public transportation system for the CTMM.

This paper presents some history and an overview of the public transportation system in the CTMM in Section 2. Section 3 provides the department's current 
methodology used for transportation developments. Activity-based and agentbased modeling is discussed in Section 4, along with a proposed integrated framework.

\section{Public transport in Tshwane}

Pretoria and its immediate surrounding regions (today known as the City of Tshwane Metropolitan Municipality (CTMM)) was founded in 1856 and is located in the Gauteng Province to the north of the City of Johannesburg. The City of Tshwane covers an area of $3200 \mathrm{~km}^{2}$, which includes East-West mountain ranges (Pyramid Koppies, Magaliesberg Mountain, Witwatersberge and a whole range of smaller hills), a number of rivers, such as the Apies river and has a population of 1.96 million according to the latest census data published by Statistics South Africa in 2001 [1].

In 1961 the National Party government declared South Africa a republic, previously a union under British rule. Residential segregation was enforced resulting in whole communities being uprooted and forced into coloured "group areas". In CTMM this largely resulted in dormitory towns such as Mamelodi and Atteridgeville situated on the periphery of the urban area and also gave rise to huge dormitory settlements far removed from the urban area, such as Mabopane, Hammanskraal, Soshanguve and KwaNdebele as illustrated in Figure 1.

The rise of these dormitory settlements resulted in the development of an outer city public transportation system deviating from the main radial inner city system initially developed to focus on the inner city in the CTMM. In addition, dispersed economic centres increased throughout the inner city resulting in a transportation system that became more focused on private transportation. Inner city public transportation system developments continued, however, in the southern parts of CTMM only as commercial, industrial and social developments were centered more around these regions. Simultaneously a separate public transportation system with a separate set of public transportation facilities were implemented to transport the people from the dormitory settlements into the city centre. This resulted in a disparity between the two systems. After the 1994 National Elections Pretoria was enlarged to include its surrounding regions and was transformed into City of Tshwane Metropolitan Municipality. It was emphasized that the entire CTMM should be integrated on all socio-economic aspects, which posed immense challenges in respect of existing disparate transportation systems.

Currently the public transportation system remains disparate, requiring the system to still be reconsidered, redesigned and optimized taking into consideration not only the current and future transportation demands but also numerous issues as a result of the past political regimes. These issues include the lack of work opportunities within the previously disadvantaged areas, necessitating workers to travel to work or get potential work outside their area of residence, access time to the nearest public transportation service of choice ranges between 5.4 and 115 minutes, $25 \%$ of the population travels more than 60 minutes to work and $42 \%$ of the population spends more than $10 \%$ of their personal income on traveling 


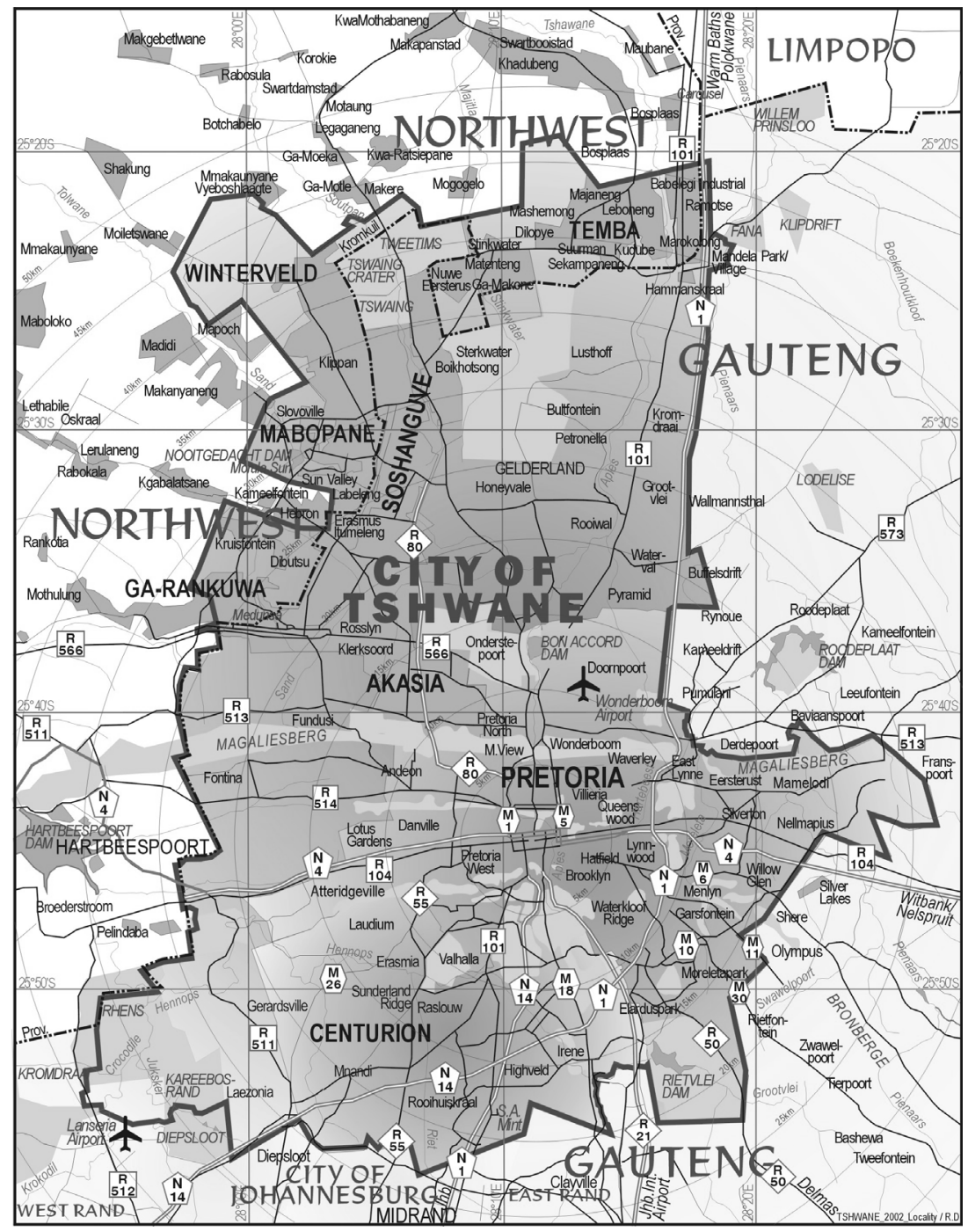

Figure 1: City of Tshwane Metropolitan Municipality locality map.

to work. Furthermore, the disperse economic centres across the city focuses on elevating the pressure on the city centre, ensuring job opportunities right across the city whereas the transportation system still focuses on bringing people into the city centre instead of transporting them directly to the disperse centres.

The current public transportation system consists of three modes: trains, buses and the unregulated para-transit (minibus) system. It captures only $47.4 \%$ of the entire transportation market, which does not comply with the $80 \%$ target set by the Department of Transport.

WIT Transactions on The Built Environment, Vol 89,(C) 2006 WIT Press www.witpress.com, ISSN 1743-3509 (on-line) 


\subsection{MetroRail}

The rail service consists of a ring rail around the $\mathrm{CBD}$, with lines running from the outskirts of the CTMM to the central Pretoria area. It has 14 intermodal changes and 24 stations. The 2002 Rail Passenger Census illustrated that Pretoria, Pretoria West and Mabopane Stations are the most utilized train stations in City of Tshwane Metropolitan Municipality (CTMM) with daily passenger counts of 163400,120500 and 86400 respectively.

The current rail commuter service provided by Metro Rail under contract with the South African Rail Commuter Corporation (SARCC) is severely under utilized and is in need of more effective and cheaper feeder services. $70 \%$ of rail passengers walk to and from train stations with an average walking time ranging between 20 and 115 minutes. $20 \%$ of rail passengers use taxis and approximately $8 \%$ make use of bus services to access the trains [1].

\subsection{Independent bus operators}

Bus services are supplied from 14 depots, 23 major terminals, 25 primary bus stops and a large amount of secondary bus stops. 121000 passengers are transported daily from the outskirts of CTMM into the central city by means of nine operators. The inner city travel demand is managed by the Public City Transport (PCT) bus service, owned by the CTMM. The PCT bus service currently transports approximately 8200 adults and 7100 learners during the morning peak period.

Ten bus operators in total provide the main commuter service, by means of 1491 buses traveling on 2059 routes, illustrating an evident lack of capacity [1].

\subsection{Taxis as a paratransit mode}

The paratransit system active in the CTMM captures 50\% of the public passenger transportation trips and consist of 43 minibus taxi and 19 different metered taxi associations providing services from 179 ranks. The CPTR 2003 survey could only identify 10750 minibus taxis traveling on 462 minibus taxi routes and approximately 500 metered taxis due to the fact that the surveys were mainly rank-based departure surveys which do not include the non rank-based and local suburban trips. Metered taxis provide radius based services from main commercial centres, shopping centres and hotels, which are difficult to monitor [1].

Official time schedules do not exist for these services due to its unregulated nature. Only a modicum of official taxi stops exists on the routes traveled by the taxis. Each pedestrian can become a potential stop if the appropriate hand signal is used indicating the pedestrian's need to be picked up. The paratransit system poses safety risks due to the fact that taxis don't sufficiently adhere to the traffic laws as they stop anywhere for passengers to embark or disembark, resulting in traffic congestion and accidents. Even though the paratransit taxi service is more expensive than the bus service, people prefer using the taxi service due to its availability, accessibility and increased frequency. 


\section{Current planning methodology}

In attempt to integrate the disparate public transportation systems, forecast the population growth and possible future travel demand, and provide an service that meets the current demand expectations, CTMM has strategic planning and operational planning departments. These two departments function independently as the strategic planning department is concerned with future transportation networks, network loading constraints, road flow volumes and road infrastructures whilst the operational planning department is more concerned with the time schedules of the different public transportation service providers and ensuring that demand for public transport in the different regions are met. The increase in travel demand over the last 10 years placed immense amount of pressure on the transportation planning departments due to insufficient resource capacity available to meet the increasing demand. The pressure on the transportation planning department results in the use of suboptimal transportation networks just to meet the increasing demand.

\subsection{Strategic}

The City of Tshwane Metropolitan Municipality's strategic planning department uses the Four Stage Model (FSM) [2] in order to model the current transportation network with the aim to forecasts future travel demands taking into consideration population growth, socio-economic developments and future events that will have an effect on the travel demand. The FSM was designed in the 1950s primarily as a tool to be used for forecasting future demand and performance of a transportation system [3] and consists of the following four stages:

Trip Generation Provides the propensity to travel and estimates the trip productions and attractions separately according to each zone. The FSM is trip based and not activity based and requires an extensive amount of data gathering in order to do trip generation calculations.

Trip Distribution Trip production and trip attraction distributions, generated in the trip generation stage, are matched in order to reflect zonal travel demand and produce an origin-destination table.

Modal Split Origin-destination tables are factored into mode specific trip tables by using vehicle occupancies and total person trips for a specific mode whilst ignoring trips made by other modes.

Route Assignment Origin-destination matrices are loaded unto the transportation networks, using a number of different factoring techniques in order to reflect true vehicle route occupancy.

\subsection{Operational}

The time schedules and routes as designed for the 1970s are still used today even though the network flow volumes have increased and new socio-economic centres 
have developed over the last 35 years. This inhibits bus operators to adhere to the departure and arrival times specified in published time schedules whilst resulting in an unreliable service. The current procedure followed by the operational planning department when demand for a route is reported or when low route utilization is realized is merely to assign a route to, or eliminate a route from the transportation network according to the demand or the lack of demand, taking into consideration the vehicle capacity and the capital available. The unregulated paratransit system is merely monitored by the operational planning department in order to obtain information and data such as routes traveled and utilization figures. Informal planning is currently done in the unregulated paratransit system service. As far as the rail system service is concerned the operational planning department attempts to keep the trains maintained and schedules updated to meet demand.

\section{Proposed framework}

In assisting the CTMM to redesign the current disparate public transportation systems different modeling approaches have been researched, one of which is the Four Stage Model (FSM) [2].

The Four Stage Model was primarily developed for the analysis of highways and have also been made suitable for use in assessing major rail infrastructure. Allaman, Tardiff and Dunbar (as cited by Recker et al. [4]) stated that the conventional approaches to model travel behavior still offers operational models which perform well in certain well-defined situations. However according to Bates [5] the FSM is less suitable for the investigation of global, highly flexible policies (such as public transport fares) or policies that are likely to involve substantial change in travel response. McNally [6] and Bates [5] builds on the weaknesses and limitations of trip-based models such as the FSM as identified by Heggie [7], Jones [8], Burnett and Thrift [9], Burnett and Hanson [10], Recker et al. [4] and USDOT [11]. These shortcomings include:

- Limited consideration is given to the changes that behavioural changes (possibly due to pricing structures or policies) could have on the "time of day" profile.

- Personal factors affecting modal choice are not generally taken into account, primarily because of the limited dimensions relating to the traveller.

- Very often elementary modal choices such as walking or cycling are not considered or treated, apart from its accessing nature to the rest of the transport infrastructure.

- The model does not include an equilibrium focused iterative execution due to the burden placed upon model computations

- Travel choices are based upon a choice process within the model instead of on a range of more complex constraints that delimits choice, this in turn results in misrepresentation of traveler behaviour.

- It is inadequate in terms of its specification of the relationship between travel activity participation and transportation scheduling, which also includes activity links and interpersonal limitations. 
- As the model is based almost solely on "utility maximization" it neglects the substantial evidence related to alternative travel activity decisions based on household dynamics, knowledge and information levels, complexity of choice, habitual activity as well as specifications of a discontinuous nature.

- An inability exists in the establishment of distinct choice alternatives available to the traveler within a constrained environment, in turn resulting in a misspecification of choice available to the traveler.

- A large focus is placed on individual trips, which largely ignores the spatial and temporal interrelationship between traveler's activity patterns and all trips.

Other modeling approaches used to design and model transportation systems were also researched, such as the standard modeling approach where household trip rates or person trip rates of different type of persons are estimated based on certain characteristics [5].

Models where car ownership models are used extensively in transportation prediction models as reviewed by Bates [5].

Mackett and Edwards [12] developed an expert system that can be used to assist in the decision making process in which cities investigate the development of a new public transportation system.

In the past decade an activity based modeling approach to travel behaviour has surfaced in response to the prevalent dissatisfaction with trip-based demand models. The rationale underlying activity approach has been discussed by many authors (Heggie (1978), Heggie and Jones (1978, 1979, 1981), Jones et al. (1983) and Kutter (1981) as cited by Recker et al. [4]).

Activity based modeling is based on the fact that travel decisions are determined by a compilation of activities that forms a program of involvement and can not be examined on an individual trip bases as used in trip based models. The set of activities and trips actually performed comprise of an individual's activity pattern. The decisions process, behavioral rules and environment in which they are valid, together constrain the formation of these patterns and characterize complex travel behavior. This approach is capable of modeling complex traveler responses that ranges from simple modal shifts to more complex adaptations involving trip consolidation.

\subsection{Activity based theoretical framework}

Recker et al. [4] constructed a recommended theoretical framework that placed travel on a broader context than in individual-trip approaches and provided an explanation of complex travel behaviour. A modelling system based on comprehensive activity was improved by Recker et al. [13] offering a possible direction for the implementation of the theoretical issues.

Firstly, travel demand is described by a set of required activities performed by an individual, which in turn results travel that can be seen as the product of scheduling these activities according to time available in a daily, weekly or monthly period. Secondly, the individual's entire activity pattern is focused 
on, in which the theoretical framework integrates the interrelationships between activity scheduling decisions that can be made by the individual. Thirdly, the theoretical model integrates consequences on travel behaviour caused by spatial and sequential characteristics of the transportation and activity systems. Fourthly, several household constraints are utilised in order to depict the travel interdependencies between individual members of each household. Lastly, the traveller's perceptual thresholds and limited evaluation capability are recognised in order to minimise the traveller's choice set to a size that can more easily be accommodated by current choice models.

\subsection{Agent-based modeling}

Agent based modeling developed due to interactions between "agent vs. system" and "agent vs. agent" being extremely complex and difficult to express analytically. The basic premise of Agent Based Modeling is to specify the principles of behaviour and principles of interaction amongst various individual agents at a micro level, whilst following this up with simulation exercises where the outputs and results of critical mass are tested in order to evaluate the effect of such principles on large population sections. Agent Based Modeling further has the innate capacity to generate intricate, yet interesting, emerging properties that arise from the intricacy of system interactions (and not as much from agent behaviour), which very often is the reason why results gained from an agent based model can't be formally deduced on a purely mathematical basis [14].

A transportation system is considered to have medium to low abstraction levels and falls within the range of problems that can be successfully dealt with by simulation modeling due to its operational and tactical nature and the high level of detail modeling required. Network and transportation simulations can deal effectively with schedules, latencies, capacities and loading/unloading and processing times and can also model macro level traffic and transportation models which does not consider individual vehicles, but instead model traffic volumes [15].

\subsection{Integration of modeling approaches}

In the attempt to redesign the current disparate public transportation system and work towards an integrated public transportation system for the CTMM elements from work of Ortuzar and Willumsen [2], Recker et al. [4], Dia [16] and Hickman and Bernstein [17] is integrated. The theoretical approach is used in correlation with the agent-based simulation modeling approach described by Srbljinovic and Skunca [14] and Borshchev and Filippov [15] in order to construct a functional agent based simulation model which aspires to give a true representation of the current transportation system.

The proposed framework in order to attempt redesigning the public transportation system consists firstly of the trip generation and trip distribution 
stages of the Four Stage Model [2] which is used in order to attain an origindestination matrix for the CTMM region of study.

The origin-destination matrix obtained is thereafter used in conjunction with data acquired from Statistics South Africa and the Integrated Transportation Plan [1] in order to construct possible activity and travel choice sets in order to model complex travel behaviour according to the theoretical development of Recker et al. [4].

The activity and travel choice sets are assigned to agents in order to create activity patterns for the individual agents. The agent intellectual mental model as used by Dia [16] is integrated into the complex travel behavioural model in order to give a true representation of decisions made by agents based on their beliefs, capabilities, commitments and behavioral rules.

The current transportation network, routes and time schedules are imported into an agent based simulation model together with the path choice model that incorporates time dependent and stochastic transit service characteristics [17].

The individual agents are distributed over the CTMM region of study and interactions between agents and the system and agents with one another are simulated.

A fully functional simulation model is merely the first step in the attempt to redesign and integrate the public transportation system of CTMM.

\section{Conclusion}

In this paper the authors challenge the obsolete planning processes based solely on the Four Stage Model proposed by Ortuzar and Willumsen [2]. To accommodate South African particularities, a planning approach is required that addresses commuters ability to request public transport trips using a paratransit system. Such a system increases the complexity as each commuter has the possibility to become a node in the public transport network where embarkation/disembarkation takes place.

The Four Stage Model is integrated with both activity-based and agent-based modeling approaches to result in an approach with more realistic representation of the current public transport network in CTMM.

Future research will be focused on developing a various transportation networks which will be imported into the simulation model to find an optimal network not only for the current scenario but also for future planning.

\section{References}

[1] CTMM, Integrated transport plan 2004-2009. Technical report, City of Tshwane Metropolitan Municipality, 2005.

[2] Ortuzar, J.D. \& Willumsen, L.G., Modelling Transport. John Wiley and Sons Ltd, 3rd edition, 2001.

[3] McNally, M.G., The four-step model. Handbook of Transport Modelling, eds. 
D.A. Hensher \& K.J. Button, Pergamon, chapter 3, pp. 35-52, 1st edition, 2000.

[4] Recker, W.W., McNally, M.G. \& Root, G.S., A model of complex travel behavior: Part i - theoretical development. Transportation Research A, 20(4), pp. 307-318, 1986.

[5] Bates, J., History of demand modelling. Handbook of Transport Modelling, eds. D.A. Hensher \& K.J. Button, Pergamon, chapter 2, pp. 11-34, 1st edition, 2000.

[6] McNally, M.G., Activity based approach. Handbook of Transport Modelling, eds. D.A. Hensher \& K.J. Button, Pergamon, chapter 2, pp. 11-34, 1st edition, 2000.

[7] Heggie, I., Putting behavior into behavioral models of travel. Operatioanl Research Society, 29(6), pp. 541-550, 1978.

[8] Jones, P., New approaches to understanding travel behaviour: the human activity approach. Behavioral Travel Modeling, eds. D.A. Hensher \& P. Stopher, Croom Helm: London, 1979.

[9] Burnett, K.P. \& Thrift, N., New approches to understanding traveller behavior. Behavioral Travel Modeling, eds. D.A. Hensher \& P. Stopher, Croom Helm: London, 1979.

[10] Burnett, K.P. \& Hanson, S., Rationale for an alternative mathematical approach to complex human behavior. Transportation Research, 723, pp. 11-24, 1979.

[11] USDOT, Activity-based travel forcasting conferece proceedings. Report dott-95-13, U.S. Department of Transportation, Washington, DC, 1997.

[12] Mackett, R. \& Edwards, M., An expert system to advice on urban public transport technologies. Computer, Environmental and Urban Systems, 20(4/5), pp. 261-273, 1996.

[13] Recker, W.W., McNally, M.G. \& Root, G.S., A model of complex travel behavior: Part ii - an operational model. Transportation Research A, 20(4), pp. 319-330, 1986.

[14] Srbljinovic, A. \& Skunca, O., An introduction to agent based modeling and simulation of social processes, 2003.

[15] Borshchev, A. \& Filippov, A., From system dynamics and discrete event to practical agent based modeling: Reasons, techniques, tools. The 22nd International Conference of the System Dynamics Society, Oxford, England, July 25-29, 2004.

[16] Dia, H., An agent-based approach to moddeling driver route choice behaviour under the influence of real time information. Transportation Reseach Part C, 10, pp. 331-349, 2002.

[17] Hickman, M.D. \& Bernstein, D.H., Transit serivce and path choice models in stochastic and time-dependent networks. Transportation Science, 31(2), pp. 129-146, 1997. 